\title{
Nitric oxide synthase inhibition augments acute allergic reactions in the pig airways in vivo
}

\author{
R.J.M. Middelveld, W.C.G. Zetterquist, D. Bergman, K. Alving
}

Nitric oxide synthase inhibition augments acute allergic reactions in the pig airways in vivo. R.J.M. Middelveld, W.C.G. Zetterquist, D. Bergman, K. Alving. (C)ERS Journals Ltd 2000.

ABSTRACT: The aim of this study was to examine the effects of nitric oxide synthase inhibition on antigen- and histamine-induced acute airway reactions, in order to clarify the possible modulating role of NO.

Twelve specific-pathogen-free pigs (sensitized with Ascaris suum antigen) were challenged with an antigen aerosol during mechanical ventilation and anaesthesia. Six pigs were pretreated with $N^{\mathrm{G}}$-nitro-L-arginine (L-NA, $10 \mathrm{mg} \cdot \mathrm{kg}^{-1}$ ), a NO synthase inhibitor, $30 \mathrm{~min}$ before challenge. In separate experiments, seven sensitized pigs received histamine $(5 \mathrm{mg}$ ) aerosols before and after L-NA treatment.

It was found that pretreatment with L-NA resulted in an enhanced airways resistance response to antigen (areas under the curve 0-90 min were (mean \pm SEM) $1,119 \pm 160$ versus $555 \pm 56\left(\mathrm{cmH}_{2} \mathrm{O} \cdot \mathrm{L}^{-1} \cdot \mathrm{s}^{-1} \cdot \mathrm{min}\right.$ for controls, $\mathrm{p}<0.05$ (Mann-Whitney $\mathrm{U}$ test), whereas this response to histamine was not affected by L-NA. Moreover, L-NA pretreatment significantly enhanced total protein $\left(1.85 \pm 0.43\right.$ versus $0.31 \pm 0.06 \mathrm{~g} \cdot \mathrm{L}^{-1}$, $p<0.01)$ and histamine levels $(42.8 \pm 16.0$ versus $2.6 \pm 0.8 \mathrm{nM}, \mathrm{p}<0.05)$ in bronchoalveolar lavage fluid $45 \mathrm{~min}$ after antigen challenge.

In conclusion, this study showed that $N^{\mathrm{G}}$-nitro-L-arginine enhanced reactions occurring during the acute allergic reaction in pigs in vivo. This indicates a protective role of nitric oxide, which might occur through downregulation of histamine release from mast cells rather than a direct bronchodilating effect of nitric oxide.

Eur Respir J 2000; 16: 836-844.
Dept of Physiology and Pharmacology, Karolinska Institutet, S-171 77 Stockholm, Sweden.

Correspondence: R.J.M. Middelveld, Dept of Physiology and Pharmacology, Karolinska Institutet, S-171 77 Stockholm, Sweden. Fax: 468332278

Keywords: Ascaris suum

bronchial circulation

histamine

mast cell

nitric oxide

$N^{\mathrm{G}}$-nitro-L-arginine

Received: December 311999

Accepted after revision August 32000

This study was supported by the Swedish Medical Research Council (project No. 10354), the Swedish Heart-Lung Foundation, the Swedish Foundation for Allergy Research and Health Care Science and AstraZeneca, Lund, Sweden.
Nitric oxide is produced endogenously by a family of nitric oxide synthases (NOSs) and is thought to be an important modulator of airway function in normal and inflamed airways [1]. There is increasing evidence that endogenously produced NO has effects on the airways that can be either favourable or deleterious depending on the type of NOS that is activated [2].

NOS exists in a constitutive (cNOS) and an inducible form (iNOS) [3]. cNOS is expressed in neurons and endothelial cells of the airways and generates NO in small amounts, which are thought to have a modulating effect on vascular and airway tone [4,5]. iNOS is found in epithelial and inflammatory cells of the airways and is induced by exposure to pro-inflammatory cytokines [3, 6]. iNOS generates 1,000 -fold higher amounts of NO than cNOS and may be responsible for the harmful effects of NO by being involved in plasma exudation (although the role of NO in vascular leakage is controversial), eosinophilic inflammation $[7,8]$ and formation of toxic radicals [1].

In the acute allergic reaction, endogenous $\mathrm{NO}$ has been suggested to play a protective role; this is indicated by small-animal studies, performed on guinea-pigs, which show that inhibition of NO production with NOS inhibitors increases airway responsiveness to allergen and histamine challenge $[9,10]$. The mechanisms for this have not been pinpointed. It has been suggested that $\mathrm{NO}$ would act primarily as a bronchodilator through a direct effect on bronchial smooth muscle $[9,11]$. However, another explanation could be that $\mathrm{NO}$, like prostaglandin $\mathrm{E}_{2}$ [12], is capable of downregulating the activity of the mast cell. This was shown by the fact that sodium nitroprusside, a nitric oxide-generating drug, is able to inhibit the release of histamine and tryptase from human mast cells [13]. Moreover, NOS inhibition has been shown to increase histamine release from mast cells [14].

The aim of the present study was to examine the role of NO in the acute allergic reaction in a large-animal model and study the mechanisms by which NO exerts its effects. This was achieved by inhibiting endogenous NO production with $N^{\mathrm{G}}$-nitro-L-arginine (L-NA), a nonselective NOS inhibitor, before airway challenge with allergen or histamine in the allergic pig. Since it could be expected that NOS inhibition would cause marked cardiovascular effects, changes in the systemic, pulmonary and bronchial circulations were followed.

\section{Methods}

The experiments described in this study were performed according to regulations issued by the Swedish National Board for Laboratory Animals and were approved by the local Ethics Committee for animal research. 


\section{Animals and sensitization}

A total of 19 specific-pathogen-free pigs of either sex (Seropig; Vallrums Lantbruks AB, Ransta, Sweden) were used in the present study, with a mean body weight of $17.5 \pm 0.8 \mathrm{~kg}$. Twelve pigs were sensitized via subcutaneous injections of Ascaris suum antigen (for further details see [15]) in a suspension of aluminium trihydroxide at the ages of 3 and 7 weeks. Before starting the experiments, the pigs were classified according to their responsiveness to $50 \mu \mathrm{L}$ of allergen injected into the skin. They were then divided into a control group $(n=6)$ and a L-NA treated group $(n=6)$. These groups did not differ in their responsiveness to skin tests. The remaining seven pigs were sensitized with Ascaris suum in the same way, after which they were used for histamine challenges.

\section{Anaesthesia and surgical preparation}

One to two weeks after sensitization, the pigs were premedicated with ketamine hydrochloride (Parke-Davis, Barcelona, Spain; $20 \mathrm{mg} \cdot \mathrm{kg}^{-1}$ i.m. $)$ and atropine $(0.5 \mathrm{mg})$, and then anaesthetized with pentobarbital sodium (Apoteksbolaget, Umea, Sweden; $15 \mathrm{mg} \cdot \mathrm{kg}^{-1}$ i.v.) through an ear vein. Anaesthetic level was evaluated by applying pain stimuli to the digital skin with forceps. Pancuronium bromide (Pavulon; Organon, Boxtel, the Netherlands; 0.2 $\mathrm{mg} \cdot \mathrm{kg}^{-1}$ i.v.) was administered for muscle relaxation. After tracheostomy, the pigs were mechanically ventilated using a Servo 900 ventilator (Siemens-Elema, Solna, Sweden). The pigs received a mixture of air and oxygen (inspiratory oxygen fraction ranged 21-26\%). A femoral vein was cannulated for fluid and drug infusions and through this cannula the animals received a continuous infusion of pentobarbital $\left(10 \mathrm{mg} \cdot \mathrm{kg}^{-1} \cdot \mathrm{h}^{-1}\right.$ i.v. $)$ and pancuronium bromide $\left(0.6 \mathrm{mg} \cdot \mathrm{kg}^{-1} \cdot \mathrm{h}^{-1}\right.$ i.v. $)$ throughout the experiments. Femoral arteries were cannulated for blood sampling and measurements of mean arterial pressure (MAP) and cardiac frequency $(f \mathrm{c})$. The other femoral vein was cannulated and an Edwards Swan-Ganz balloon-tipped thermodilution catheter (Baxter, Irvine, CA, USA; $1.5 \mathrm{~mL}$ ) was inserted into the pulmonary artery for continuous registration of pulmonary arterial pressure (PAP). The right ureter was cannulated for urine sampling. After a right-side thoracotomy, an ultrasonic flow probe (Transonic System, Ithaca, NY, USA) was placed around the bronchial artery for absolute bronchial blood flow (BBF) measurements. Respiratory pressure was measured through a connection of the tracheal tube to a pressure transducer (Kent Scientific, Litchfield, CT, USA). A heated pneumotachometer (Hans Rudolph, Kansas City, MO, USA) was used to measure airflow. Respiratory pressure and airflow signals were fed into a pulmonary computer (AP 200; ConMeTech AB, Uppsala, Sweden) for calculations of airway resistance (Raw) and dynamic lung compliance $(C \mathrm{~L}$, dyn). Raw was calculated using the following formula: (peak pressure-pause pressure)/end inspiratory flow. The resistance of the tracheal tube was not subtracted for the calculation of Raw. $C$ L,dyn calculations were performed as follows: expiratory tidal volume/(pause pressure-end expiratory pressure). All measurements were recorded on a Grass polygraph (Grass Instrument, Quincy, MA, USA). Ringer's solution, containing $0.5 \%$ glucose, was given throughout the experiment at a rate of $\sim 400 \mathrm{~mL} \cdot \mathrm{h}^{-1}$.
Heparin, to a total of 1,000 IU (Løvens, Ballerup, Denmark), was given through the cannulae before the start of the experimental procedure. Body temperature was measured with a rectal thermometer and maintained at 38$39^{\circ} \mathrm{C}$. Arterial blood gas tensions and $\mathrm{pH}$ were regularly monitored using an automatic blood gas analyser (ILS 1610; Instrumentation Laboratory, Lexington, MA, USA) and set to physiological levels at baseline. The settings were not changed thereafter. After the experiments were completed, the pigs were sacrificed with an overdose of pentobarbital sodium.

\section{Experimental protocol and sample collection}

L-NA, $10 \mathrm{mg} \cdot \mathrm{kg}^{-1} i . v$. was dissolved in $20 \mathrm{~mL}$ saline and administered as an infusion over $5 \mathrm{~min}$ in six sensitized animals 35 min before challenge with Ascaris antigen. Six control animals received an infusion of saline. Ascaris extract was diluted in a standardized way (crude extract, diluted twice in saline) to a volume of $2 \mathrm{~mL}$ and this solution was delivered to an ultrasonic nebulizer (NB 108; Engström Medical, Stockholm, Sweden). The nebulizer produced an aerosol which was delivered to the pig between the ventilator and the endotracheal tube over a period of 3-5 min. Bronchoalveolar lavage (BAL) was performed 45 min after Ascaris challenge by inserting a fibreoptic bronchoscope for paediatric use (Olympus, Tokyo, Japan) into the right middle lobe of the lungs; 20 $\mathrm{mL}$ saline $\left(37^{\circ} \mathrm{C}\right)$ was used. MAP, $f$ c, PAP, $C$ L,dyn, Raw and $\mathrm{BBF}$ were continuously recorded on a Grass Polygraph. Blood and urine samples were taken at regular time intervals. The experiments were terminated $90 \mathrm{~min}$ after Ascaris challenge.

In an additional set of experiments, seven pigs received a histamine aerosol (5 mg in $0.5 \mathrm{~mL}$ saline) without prior pretreatment with L-NA and then again $30 \mathrm{~min}$ after pretreatment with L-NA as above. A 3-h interval was allowed between histamine challenges. Observations were made during the $90 \mathrm{~min}$ after challenge in the control situation, and the 75 min after L-NA pretreatment.

After collection, the blood samples were mixed with ethylene diamine tetra-acetic acid to a final concentration of $10 \mathrm{mM}$. The blood, urine and BAL samples were kept on ice until being centrifuged for $20 \mathrm{~min}$ at $170 \times g$ at $4^{\circ} \mathrm{C}$. The supernatants were divided into aliquots and stored at $-80^{\circ} \mathrm{C}$ until further analysis.

\section{Sample analyses}

Differential counts of the BAL cytospins were performed after fixation with $100 \%$ methanol for $5 \mathrm{~min}$ and staining with May-Grünwald (Sigma, St. Louis, MO, USA) for $5 \mathrm{~min}$ and Giemsa (Merck) for $15 \mathrm{~min}$. Three hundred cells per cytospin slide were counted.

The total protein content of the BAL fluids was measured with the Pierce bicinchoninic acid (BCA) protein assay (Pierce Chemical Company, Rockford, IL, USA), which uses enhanced colorimetric detection of $\mathrm{Cu}^{+}$ produced in the reaction of protein with alkaline $\mathrm{Cu}^{2+}$. Urine creatinine concentrations were determined using a colorimetric assay (Sigma). BAL and urine histamine levels were measured with a radioimmunoassay kit (Immunotech, Marseille, France). Histamine levels in urine are expressed per mole of creatinine. 


\section{Calculations and statistics}

Data are presented as mean \pm SEM. Bronchial vascular tone is presented as bronchial vascular conductance (BVC), calculated from blood flow divided by MAP. Statistical analyses were performed using the MannWhitney U-test to detect significant differences between treatments at certain time-points. Data were considered significant at a $p$-value of $<0.05$. A trend was accepted at $\mathrm{p}<0.1$. Friedman tests were used to detect differences over time and thereafter Dunn's multiple comparison test was performed to detect at which time-points the differences existed. The Spearman rank test was used to find correlations between different parameters. Analyses were performed using a commercial software package (Prism; Graphpad, San Diego, CA, USA) for the Macintosh computer.

\section{Results}

\section{Bronchial reactivity}

L-NA infusion caused an increase in baseline $R$ aw, which was significant at $0 \mathrm{~min}$. Ascaris aerosol resulted in a profound increase in Raw of rapid onset in all animals (fig. 1a). In animals pretreated with L-NA, the allergeninduced airway reaction was significantly enhanced compared to the control group. This was indicated by the area under the curve for the increase above baseline in $R$ aw 0-90 min, which was $1,119 \pm 160 \mathrm{cmH}_{2} \mathrm{O} \cdot \mathrm{L}^{-1} \cdot \mathrm{s}^{-1} \cdot \mathrm{min}$ in the L-NA group and $555 \pm 56 \mathrm{cmH} \mathrm{H}_{2} \mathrm{O} \cdot \mathrm{L}^{-1} \cdot \mathrm{s}^{-1} \cdot \min$ in the control group $(\mathrm{p}<0.05$, Mann-Whitney U-test). After histamine challenge (fig. 1b), the animals in both the LNA and control situations showed a rapid increase in $R$ aw. L-NA did not change the airway reactivity to histamine challenge, which is also indicated by the areas under the curves, 0-75 min, which were $1,150 \pm 247 \mathrm{cmH}_{2} \mathrm{O} \cdot \mathrm{L}^{-1}$. $\mathrm{s}^{-1} \cdot \mathrm{min}$ in the L-NA situation and $1,056 \pm 230 \mathrm{cmH}_{2} \mathrm{O}$. $\mathrm{L}^{-1} \cdot \mathrm{s}^{-1} \cdot \mathrm{min}$ in the control situation. These values did not differ significantly (Mann-Whitney U-test).

There was a slight fall in baseline CL,dyn before Ascaris challenge, which was similar in both groups. Ascaris challenge caused a rapidly developing decrease in $C \mathrm{~L}$,dyn, which showed a trend towards being enhanced by L-NA pretreatment at time-points 15-35 min after challenge (Mann-Whitney U-test, data not shown). The areas under the curves, 0-90 $\mathrm{min}$, were $1,130 \pm 81 \mathrm{~mL} \cdot \mathrm{cmH}_{2} \mathrm{O}^{-1} \cdot \min$ in the control group and $918 \pm 136 \mathrm{~mL} \cdot \mathrm{cmH}_{2} \mathrm{O}^{-1} \cdot \min$ in the L-NA group (nonsignificant, Mann-Whitney U-test). The change in $C \mathrm{~L}$,dyn as a result of histamine challenge was similar to that as a result of Ascaris challenge (data not shown). The areas under the curves, 0-75 min, were $1,029 \pm 134 \mathrm{~mL} \cdot \mathrm{cmH}_{2} \mathrm{O}^{-1} \cdot \mathrm{min}$ in the control situation and $856 \pm 104 \mathrm{~mL} \cdot \mathrm{cmH}_{2} \mathrm{O}^{-1} \cdot \mathrm{min}$ in the L-NA situation (nonsignificant, Mann-Whitney U-test).

\section{Blood gas levels, $\mathrm{pH}$ and base excess}

Arterial oxygen tension $\left(\mathrm{Pa}_{\mathrm{a}} \mathrm{O}_{2}\right)$ was affected by Ascaris challenge in the control and L-NA-treated groups and showed a decrease (table 1). This decrease was significantly aggravated after L-NA pretreatment 15, 30 and 45
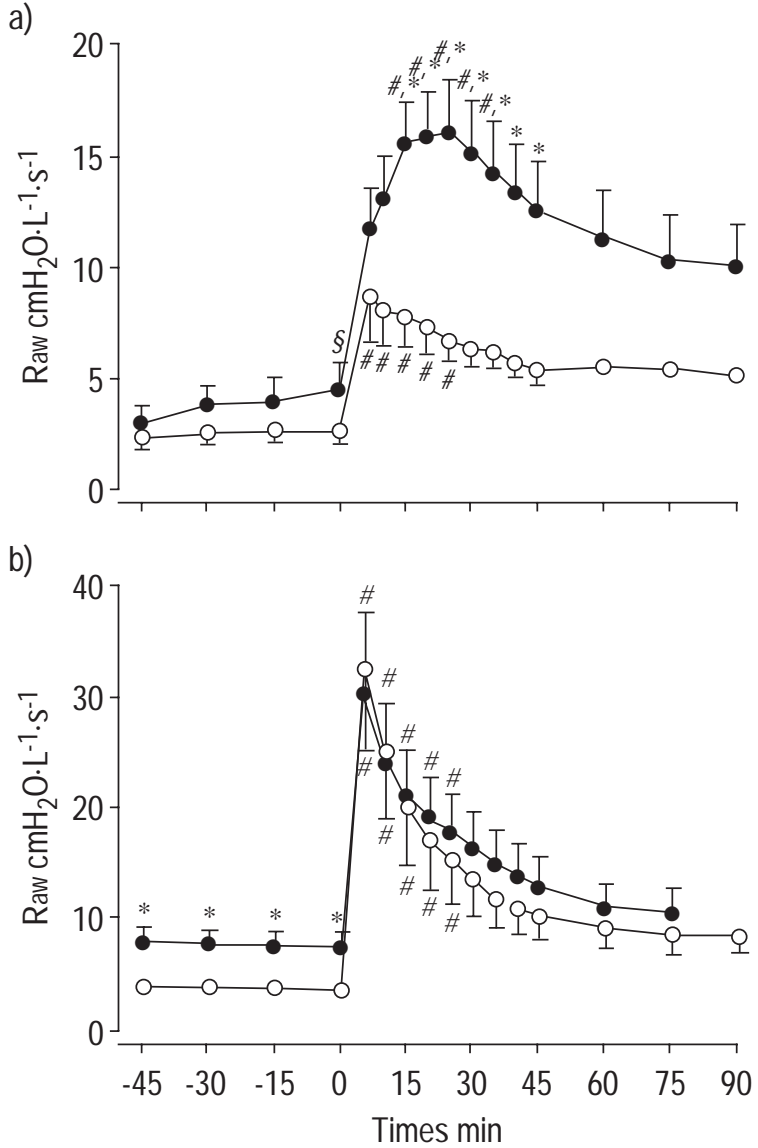

Fig. 1. - Effects of $N^{\mathrm{G}}$-nitro-L-arginine (L-NA) on airway resistance (Raw) after challenge with: a) allergen; and b) histamine. a) L-NA (10 $\mathrm{mg} \cdot \mathrm{kg}^{-1}$ ) was administered as an infusion over 5 min starting $35 \mathrm{~min}$ before challenge $(0 \mathrm{~min})(\mathrm{O} ; \mathrm{n}=6)$. Control animals $(\bigcirc ; n=6)$ did not receive L-NA. b) seven animals were challenged with histamine $(5 \mathrm{mg})$ before $(\bigcirc$; control) and after $(\bigcirc)$ L-NA pretreatment. An interval of $3 \mathrm{~h}$ was allowed between histamine challenges. Data are expressed as mean \pm SEM. *: $\mathrm{p}<0.05$ versus control (Mann-Whitney U-test); ${ }^{\#}: \mathrm{p}<0.05$ mean \pm SEM. ${ }^{*}: \mathrm{p}<0.05$ versus control (Mann-Whitney U-test); $: \mathrm{p}<0.05$
versus 0 min; ${ }^{5}: \mathrm{p}<0.05$ versus -45 min (Friedman and Dunn's multiple comparison test).

min after challenge $(\mathrm{p}<0.05$, Mann-Whitney U-tests, data for 30 and $45 \mathrm{~min}$ not shown). Histamine challenge also caused a decreased $\mathrm{Pa}, \mathrm{O}_{2}$, but $\mathrm{L}-\mathrm{NA}$ did not influence this. Ascaris challenge resulted in an increase in $\mathrm{Pa}_{\mathrm{a}} \mathrm{CO}_{2}$ (table 1 ), and this increase was significantly enhanced by L-NA at $60 \mathrm{~min}$. Histamine also caused increased $\mathrm{Pa}_{\mathrm{a}} \mathrm{CO}_{2}$, but these were not influenced by L-NA.

Arterial $\mathrm{pH}$ was also influenced by Ascaris challenge, as shown in table 1. After L-NA pretreatment, $\mathrm{pH}$ showed a gradual decrease and these $\mathrm{pHs}$ were significantly lower than the control values $45 \mathrm{~min}$ after challenge ( $\mathrm{pH} 7.37 \pm$ 0.02 in the control group and $7.21 \pm 0.04$ in the L-NA group, $\mathrm{p}<0.05$ Mann-Whitney U-test). L-NA did not affect the decreased $\mathrm{pH}$ levels seen after histamine challenge. Arterial base excess values did not change acutely after Ascaris challenge itself, but were significantly lower $45 \mathrm{~min}$ after challenge following pretreatment with L-NA $(-0.3 \pm 0.8 \mathrm{mM}$ in the control group versus $-4.1 \pm 0.9 \mathrm{mM}$ in the $\mathrm{L}-\mathrm{NA}$ group, $\mathrm{p}<0.05$ MannWhitney U-test). The base excess values did not change after histamine challenge (data not shown). 
Table 1. - Effects of $N^{G}$-nitro-L-arginine (L-NA) pretreatment on allergen- and histamine-induced changes in arterial oxygen $\left(\mathrm{Pa}, \mathrm{O}_{2}\right)$ and carbon dioxide tension $\left(\mathrm{Pa}, \mathrm{CO}_{2}\right)$ and $\mathrm{pH}$

\begin{tabular}{lccccc}
\hline & & & \multicolumn{2}{c}{ Time min } \\
\cline { 3 - 5 } & Challenge & Pretreatment & 0 & 15 & 60 \\
\hline$P_{\mathrm{a}, \mathrm{O}_{2}} \mathrm{kPa}$ & Allergen & Control & $13.7 \pm 0.7$ & $9.0 \pm 0.9^{\#}$ & $9.5 \pm 0.9^{\#}$ \\
& & L-NA & $12.3 \pm 1.1$ & $6.2 \pm 0.3^{*}, \#$ & $7.6 \pm 1.0$ \\
& Histamine & Control & $14.4 \pm 1.1$ & $8.8 \pm 0.6^{\#}$ & $12.4 \pm 0.7$ \\
& & L-NA & $12.5 \pm 0.7$ & $9.3 \pm 0.5^{\#}$ & $12.1 \pm 0.5$ \\
$\mathrm{~Pa}, \mathrm{CO}_{2} \mathrm{kPa}$ & Control & $5.0 \pm 0.2$ & $5.9 \pm 0.2^{\#}$ & $5.8 \pm 0.2^{\#}$ \\
& Allergen & L-NA & $5.5 \pm 0.3$ & $6.8 \pm 0.5$ & $7.3 \pm 0.6^{*}, \#$ \\
& & Control & $5.2 \pm 0.4$ & $6.5 \pm 0.8^{\#}$ & $5.9 \pm 0.7$ \\
$\mathrm{pH}$ & Histamine & L-NA & $5.5 \pm 0.4$ & $6.5 \pm 0.6^{\#}$ & $6.1 \pm 0.6$ \\
& & Control & $7.44 \pm 0.01$ & $7.38 \pm 0.01^{\#}$ & $7.38 \pm 0.01^{\#}$ \\
& Allergen & L-NA & $7.37 \pm 0.04$ & $7.32 \pm 0.05$ & $7.24 \pm 0.05$ \\
& & Control & $7.41 \pm 0.03$ & $7.34 \pm 0.05^{\#}$ & $7.38 \pm 0.04$ \\
& Histamine & L-NA & $7.41 \pm 0.02$ & $7.34 \pm 0.04^{\#}$ & $7.36 \pm 0.03$ \\
\hline
\end{tabular}

Data are presented as mean \pm SEM. Allergen and histamine $(5 \mathrm{mg}$ ) challenges were given as aerosols over 3-5 min starting at 0 min. One group of pigs received pretreatment with L-NA $\left(10 \mathrm{mg} \cdot \mathrm{kg}^{-1}\right)$ at $35 \mathrm{~min}(\mathrm{n}=6)$ and another group served as controls and did not receive LNA $(\mathrm{n}=6)$. Seven animals were challenged with histamine before (control) and after L-NA pretreatment. An interval of $3 \mathrm{~h}$ was allowed between histamine challenges. ${ }^{*}: \mathrm{p}<0.05$ versus control; ${ }^{\#}: \mathrm{p}<0.05$ versus $0 \mathrm{~min}$.

\section{Mediators in bronchoalveolar lavage fluid and urine}

BAL recovery volumes were $13.8 \pm 1.3 \mathrm{~mL}$ in the control group and $14.7 \pm 2.3 \mathrm{~mL}$ in the L-NA group and these values were not significantly different (Mann-Whitney Utest). No differences were found in the concentrations of different kinds of leukocytes in BAL fluid (data not shown). The concentrations of both total protein and histamine in the BAL fluid were significantly higher in the L-NA group than in the control group (fig. 2). Moreover, a significant correlation was found between the BAL fluid histamine and total protein levels of both the control and L-NA group $(\mathrm{r}=0.65, \mathrm{p}<0.05$, Spearman rank test). Conversely, no correlation was found in the allergen- a)

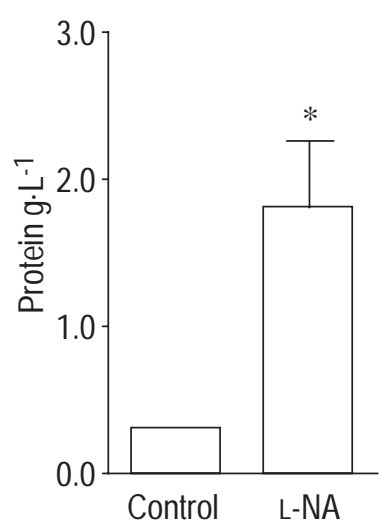

b)

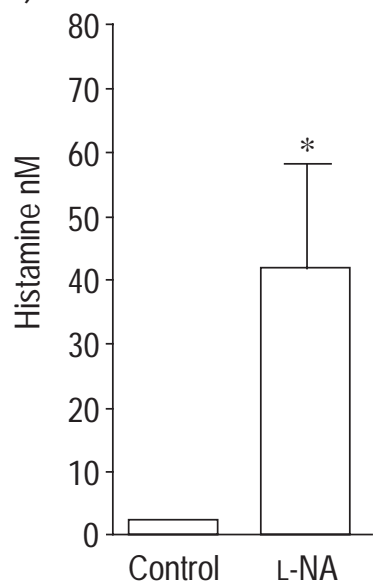

Fig. 2. - Effects of $N^{\mathrm{G}}$-nitro-L-arginine (L-NA) on: a) total protein; and b) histamine concentrations in bronchoalveolar lavage (BAL) fluid. BAL was performed $45 \mathrm{~min}$ after challenge. L-NA $\left(10 \mathrm{mg} \cdot \mathrm{kg}^{-1}\right)$ was administered as an infusion over 5 min starting 35 min before challenge $(\mathrm{n}=6)$. Allergen (Ascaris) was given as an aerosol challenge starting at 0 min. Control animals $(n=6)$ did not receive L-NA. Data are expressed as mean \pm SEM. *: $\mathrm{p}<0.05$ versus control (Mann-Whitney U-test). challenged animals between the BAL fluid histamine levels and the magnitude of the increase in Raw.

As can be seen in figure 3, Ascaris challenge caused a peak in histamine secretion in urine, and this peak was delayed after L-NA pretreatment. In the control group, the peak was seen 15 min after Ascaris challenge and, in the L-NA group, $30 \mathrm{~min}$ after Ascaris challenge. At $15 \mathrm{~min}$, the concentration of urinary histamine was significantly lower in the L-NA group than in the control group. The total amount of histamine secreted by the two groups did not differ significantly, as calculated by comparing the areas under the curves (L-NA group $6.5 \pm 1.9$ and control group $8.0 \pm 3.2 \mathrm{mmol} \cdot \mathrm{mol}$ creatinine $^{-1} \cdot \mathrm{min}^{-1}$, Mann-Whitney U-test).

\section{Cardiovascular effects}

L-NA infusion caused an increase in baseline MAP (from $123 \pm 6 \mathrm{mmHg}$ at $-45 \mathrm{~min}$ to $143 \pm 7$ at $0 \mathrm{~min}$, $\mathrm{p}<0.05$, Friedman test) compared to control (from $112 \pm 7$ to $115 \pm 8$ $\mathrm{mmHg}$, nonsignificant, Friedman test). Ascaris challenge did not influence this increased MAP, apart from a transient fall in MAP immediately after challenge which lasted 5 min (nonsignificant, Friedman test). MAP values in the LNA group were significantly higher $(\mathrm{p}<0.05$, MannWhitney U-test) than those in the control group from 30 min until 60 min after Ascaris challenge. By 90 min after challenge, the MAP values had returned to baseline $(112 \pm 20 \mathrm{mmHg})$. In the control group, no major changes occurred in MAP at any time during the experiment. Histamine challenge caused a brief increase, which lasted until $15 \mathrm{~min}$ (nonsignificant, Friedman test), in MAP in both L-NA-treated and control animals immediately after challenge, but had no long-lasting effects.

L-NA infusion caused a decrease in $f_{\mathrm{c}}$ from $167 \pm 16$ beats. $\mathrm{min}^{-1}$ at $-45 \mathrm{~min}$ to $136 \pm 8$ at $0 \mathrm{~min}$, which was significant. However, a similar baseline change in $f_{\mathrm{c}}$ was also seen in the control group (from $166 \pm 16$ to $149 \pm 10$ beats. $\min ^{-1}$ ), although this was not significant (Friedman test). Ascaris challenge resulted in an immediate transient increase in $f_{\mathrm{c}}$, in both groups. In the group that was 


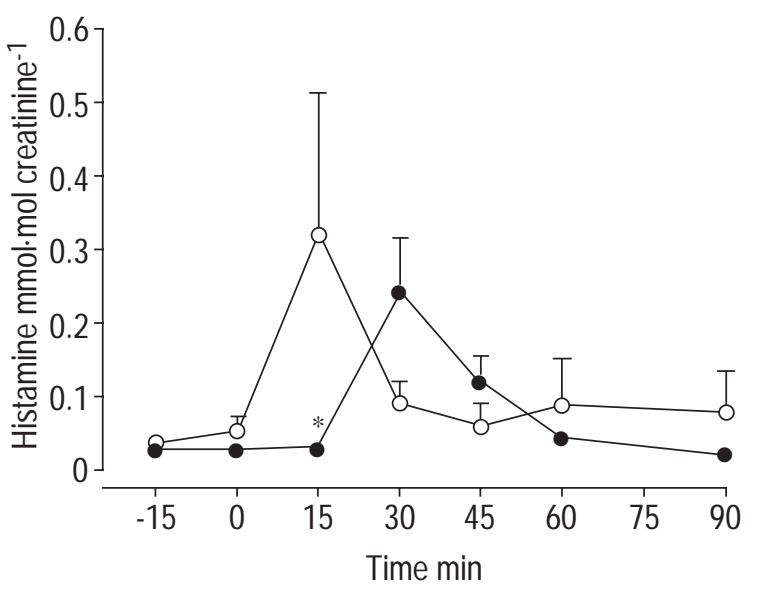

Fig. 3. - Effects of $N^{\mathrm{G}}$-nitro-L-arginine (L-NA) on urinary histamine concentrations after allergen challenge. L-NA $\left(10 \mathrm{mg} \cdot \mathrm{kg}^{-1}\right)$ was administered as an infusion over 5 min starting $35 \mathrm{~min}$ before challenge $(\mathbf{O} ; \mathrm{n}=6)$. Allergen (Ascaris) was given as an aerosol challenge starting at 0 min. Controls animals $(O ; n=6)$ did not receive $L-$ NA. Data are expressed as mean \pm SEM. *: $\mathrm{p}<0.05$ versus control (MannWhitney U-test).

pretreated with L-NA, a second, prolonged, increase was observed, which lasted until the end of the experiment. The highest value occurred at $90 \mathrm{~min}\left(216 \pm 15\right.$ beats. $\left.\mathrm{min}^{-1}\right)$ and the value in the control group at the same time-point was $149 \pm 10$ beats $\mathrm{min}^{-1}$ ( $\mathrm{p}<0.05$, Mann-Whitney U-test). Histamine challenge caused a similar immediate increase in $f_{\mathrm{c}}$ as did Ascaris challenge, but did not give rise to a long-lasting second increase after L-NA pretreatment. Endvalues after histamine challenge were $137 \pm 4$ beats $\mathrm{min}^{-1}$ in the L-NA group and $131 \pm 7$ beats $\cdot \mathrm{min}^{-1}$ in the control group at 75 min (nonsignificant).

PAP showed a slight increase after L-NA administration, but this was not significant (fig. 4a). Ascaris challenge resulted in a rapidly developing increase in PAP in both groups and this increase had a tendency to be higher in the L-NA group. The increase lasted until $\sim 45 \mathrm{~min}$ after challenge in both groups, after which the PAP remained at baseline levels until the end of the experiment. The histamine-induced changes in PAP were minor (fig. 4b). There were no significant changes over time or between the L-NA and control situation.

Baseline BBFs at $-45 \mathrm{~min}$ in the Ascaris-challenged groups were $3.93 \pm 0.92$ (control) and $5.27 \pm 1.51 \mathrm{~mL} \cdot \mathrm{min}^{-1}$ (L-NA), and, in the histamine-challenged group, $6.67 \pm 1.38$ (control) and $6.20 \pm 0.92 \mathrm{~mL} \cdot \mathrm{min}^{-1}$ (L-NA). L-NA infusion caused a significant decrease in baseline BVC. A vasodilatory response was seen after Ascaris challenge in the control animals, although this was not significant (fig. 5a). In the L-NA pretreated animals, this vasodilating response was abolished. Histamine challenge caused a long-lasting vasodilatory response in the control situation (fig. 5b). After pretreatment with L-NA, a clear-cut increase in BVC could still be seen, even though the peak BBF was much lower in these animals.

\section{Discussion}

This study shows that inhibiting NO production with LNA before the acute allergic reaction in the pig leads to enhanced bronchial reactivity to allergen. A clear

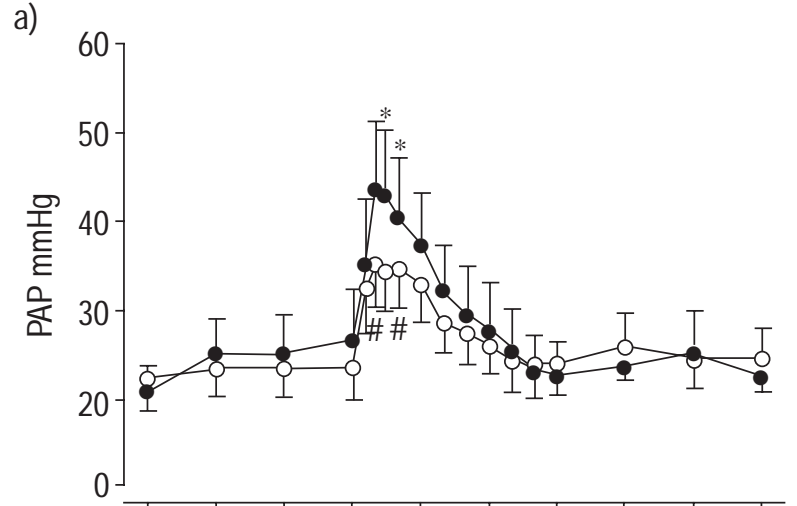

b)

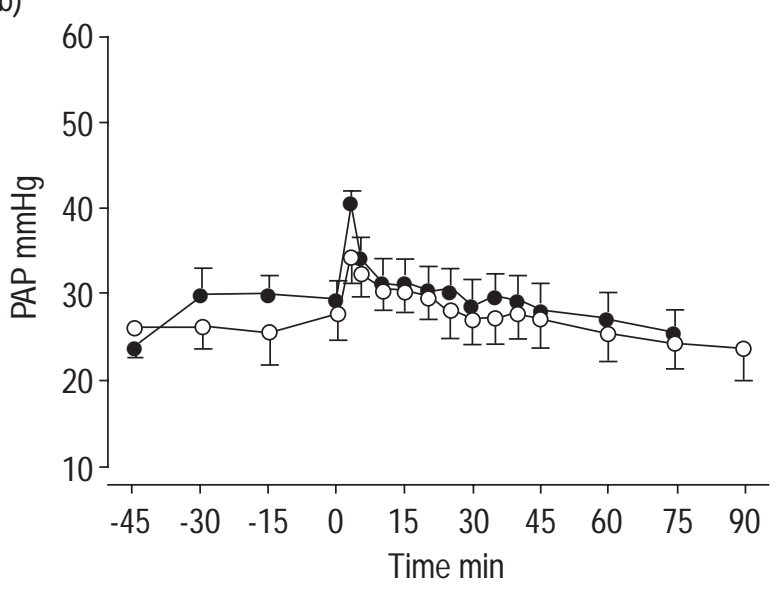

Fig. 4. - Effects of $N^{\mathrm{G}}$-nitro-L-arginine (L-NA) on pulmonary arterial pressure (PAP) after challenge with: a) allergen; and b) histamine. a) LNA $\left(10 \mathrm{mg} \cdot \mathrm{kg}^{-1}\right)$ was administered as an infusion over 5 min starting 35 min before challenge $(\mathbf{O} ; \mathrm{n}=6)$. Allergen (Ascaris) was given as an aerosol challenge starting at $0 \mathrm{~min}$. Controls animals $(\bigcirc ; n=6)$ did not receive L-NA. Data are expressed as mean \pm SEM. *: $\mathrm{p}<0.1$ versus control (Mann-Whitney U-test, trend accepted); \# $\mathrm{p}<0.05$ versus $0 \mathrm{~min}$ (Friedman test and Dunn's multiple comparison test).

difference was observed between the reactions occurring as a result of allergen challenge and those resulting from histamine challenge after L-NA pretreatment. An important mechanism for the enhancing effect of NOS inhibition on the acute allergic reaction may be increased release of mast cell mediators, in particular histamine.

The actively sensitized pig has previously been shown to be a good model for both the acute and late phase asthmatic reactions [16]. The changes in $R$ aw, $C \mathrm{~L}$,dyn and $\mathrm{BVC}$ that were observed in the present study as a result of antigen challenge are in agreement with earlier studies in the pig $[15,17]$. Moreover, pig anatomy has been found to be suitable for experimental investigations into bronchial circulation [18].

Intravenously administered L-NA alone caused several reactions in the present experiments. It was decided to administer L-NA intravenously rather than via inhalation as the aim in this study was not to reduce exhaled NO produced by the epithelium, but rather for L-NA to reach the mast cells and bronchial circulation and exert its effects there. SARTOLI et al. [19] showed that inhalation in humans was ineffective in causing $N^{\mathrm{G}}$-monomethyl-L-arginine to reach the blood circulation, and that it exerted its effects almost exclusively on the epithelium. Blocking NO 


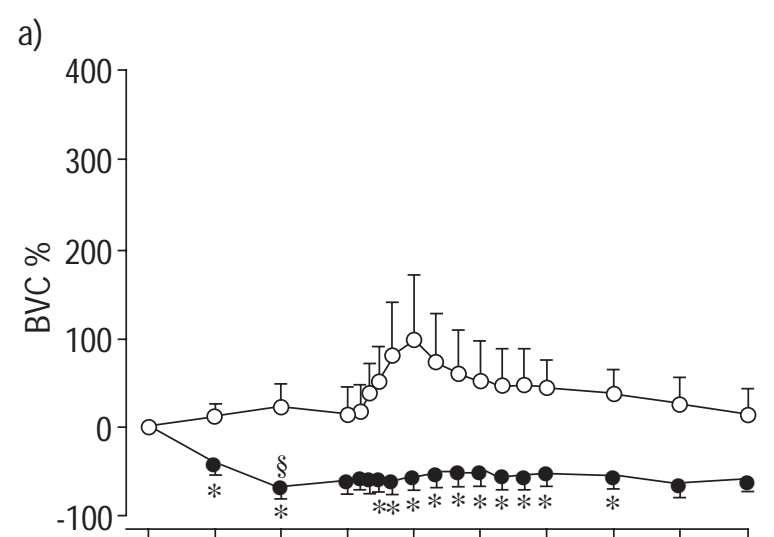

b)

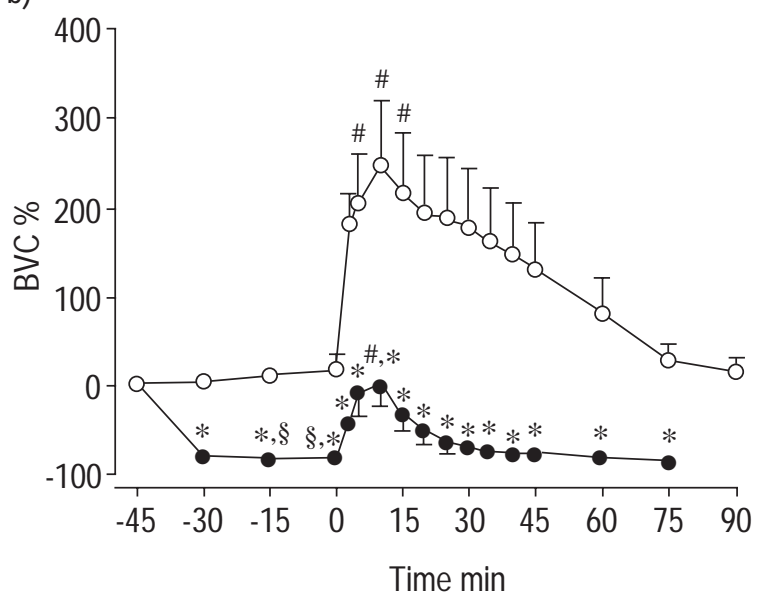

Fig. 5. - Effects of $N^{\mathrm{G}}$-nitro-L-arginine (L-NA) on change in bronchial vascular conductance $(\triangle \mathrm{BVC})$ after challenge with: a) allergen; and b) histamine. a) L-NA $\left(10 \mathrm{mg} \cdot \mathrm{kg}^{-1}\right)$ was administered as an infusion over 5 min starting $35 \mathrm{~min}$ before challenge $(\boldsymbol{O} ; \mathrm{n}=6)$. Allergen (Ascaris) was given as an aerosol challenge starting at 0 min. Controls animals $(\bigcirc$; $\mathrm{n}=6$ ) did not receive L-NA. Data are expressed as mean \pm SEM. $*$ : $\mathrm{p}<0.05$ versus control (Mann-Whitney U-test, trend accepted); ${ }^{\#}: \mathrm{p}<0.05$ versus $0 \mathrm{~min} ;{ }^{\S}: \mathrm{p}<0.05$ versus -45 min (Friedman test and Dunn's multiple comparison test).

production in the epithelium in this model would not be of much interest, especially since it has not been possible to find an increase in exhaled NO during the acute allergic reaction in the pig (unpublished observations). NO concentrations have been found to be increased in the exhaled air of asthmatics [20,21]. However, as in the pig, the acute allergic airway reaction is not associated with increased levels of exhaled NO in the human [22, 23].

Intravenous administration of NOS inhibitors has also been applied in studies on the guinea-pig [9]. In the present study $i$.v. administration of L-NA caused a decrease in $\mathrm{BVC}$, an increase in MAP and a decrease in $f_{\mathrm{c}}$. These changes could be explained by the dilatory effect of NO on blood vessels. These results are in agreement with previous studies in the pig [24]. Only slight changes in $R$ aw and $C \mathrm{~L}$,dyn were observed as a result of L-NA pretreatment. These changes could be thought to be related to the role of NO in mediating the nonadrenergic noncholinergic bronchodilator response, which has been observed in porcine trachea [25] and in human trachea and bronchus [26, 27].
Each pig in the histamine group received two histamine challenges. The first challenge was given in the control situation and the second after pretreatment with L-NA. L-NA pretreatment could not be performed before the first challenge because of its long-lasting effects. In spite of a 3 -h interval between histamine challenges, $R$ aw and $C \mathrm{~L}$,dyn had not quite returned to baseline values when L-NA was administered, but this did not seem to have an effect on the reactions to histamine challenge, as these were similar in both situations. There is no reason to believe that the second response to histamine challenge was a tachyphylactic type of response since earlier studies have given no indications of tachyphylaxis to histamine aerosol upon repeated exposure [28].

The maximal effects on Raw observed in the present study were stronger after histamine than after allergen challenge. However, when comparing the area under the curve for Raw and maximal changes in other variables such as $P \mathrm{a}_{1} \mathrm{O}_{2}$ and MAP, the effects of histamine and allergen were similar. Therefore, the authors believe that the dose of histamine administered was fairly well matched with the antigen reaction. The reason for the stronger immediate effect on Raw could be thought to result from the longer time taken to release histamine and other mediators as a result of allergen challenge compared to the rapid delivery of histamine as an aerosol. This is also indicated by the much longer lasting response of $R$ aw to allergen challenge, compared to histamine challenge.

L-NA pretreatment greatly enhanced bronchial reactivity in the acute allergic reaction in the pig, as shown in the present experiments by an increased maximal Raw and a trend to a decreased $C \mathrm{~L}$,dyn after allergen challenge. The effect of L-NA pretreatment on allergen challenge was also indicated by the areas under the curves of $R$ aw, which were significantly higher in the L-NA group than in the control group. L-NA clearly did not have this effect on histamine challenge, as maximal change and the area under the curve did not differ from each other.

In pigs pretreated with L-NA, $P \mathrm{a}, \mathrm{O}_{2}, P_{\mathrm{a}}, \mathrm{CO}_{2}$ and $\mathrm{pH}$ deteriorated severely after allergen challenge, but not after histamine challenge. Base excess values indicated metabolic acidosis as a result of L-NA administration and allergen challenge, whereas this did not occur after histamine challenge and L-NA treatment. This also shows that endogenous NO does not affect the reactions that occur in response to histamine to the same degree as those in response to allergen.

MAP was significantly increased as a result of L-NA pretreatment, but was not significantly further affected by allergen or histamine challenge. This increase in MAP is most probably a result of the inhibited NO production and the subsequent loss of the vasodilating effect of NO. Both allergen and histamine challenges caused an increase in BVC. It has been shown previously that histamine is the main bronchoconstricting and vasodilating agent in acute allergic reactions in pig airways [28]. L-NA markedly reduced the vasodilatory effect induced by allergen and histamine in the bronchial circulation, which would appear to indicate that these effects are mediated by NO release. However, this is unlikely since histamine-induced bronchial vasodilation in the pig seems to be mediated mainly through activation of sensory nerves via histamine $\mathrm{H}_{1}$ receptors and via $\mathrm{H}_{2}$ receptor activation on vessels [28], mechanisms that do not involve the release of NO 
[29]. Instead, it may be that, in a situation of high vascular tone (in the absence of endogenous NO), vasodilator mechanisms are generally reduced in an unspecific manner.

In previous studies of allergen challenge of the guineapig airways, pretreatment with a NOS inhibitor enhanced airway reactions to antigen as well as to histamine, and a primary role of $\mathrm{NO}$ as a bronchodilator was indicated [9]. This was also supported by studies that showed increased concentrations of NO in the exhaled air of guinea-pigs challenged to bronchoconstriction [30] and studies that showed a bronchodilator action of inhaled NO in guineapigs [11]. However, in the present model, only antigeninduced reactions were significantly affected by NOS inhibition and not histamine-induced reactions, suggesting that NO is of minor importance as a bronchodilator in the pig. Furthermore, NO gas has previously been shown to be a relatively poor bronchodilator in the pig [24] and in humans [31]. However, it seems that basal bronchial tone is influenced by endogenous NO, possibly through mechanisms involving inhibitory nonadrenergic noncholinergic nerves [26].

The total protein content of the BAL fluid was significantly higher in the L-NA group compared to the control group after antigen challenge, which indicates that inhibition of NO synthesis increased vascular leakage in the airways during the acute allergic reaction in the present study. Vascular leakage is thought to occur due to hydrostatic mechanisms, endothelial contraction and subsequent enlargement of the gaps in postcapillary venules [32]. Contrasting findings have been reported with regard to the role of NO in vascular leakage. $N^{\mathrm{G}}$-nitro-L-arginine methyl ester (L-NAME) has been shown to markedly attenuate the acute increase in vascular leakage in the airways in sensitized and challenged guinea-pigs [33] and, in another study, during the late-phase reaction [8]. Conversely, ERJEFÄLT et al. [34] reported that topically applied L-NAME produced subepithelial plasma extravasation into the airway lumen of the guinea-pig and, in the rat, it was found that intravenously administered L-NAME increased plasma leakage in the trachea [2]. These conflicting results may be partly explained by the different techniques used to detect vascular leakage. It may also be that NO produced in low amounts under basal conditions (e.g. in [34] and [2]) has a protective effect and that NO produced in high amounts under inflammatory conditions (e.g. in [33] and [8]) has harmful effects. Conversely, it may be that NO is not an important mediator of vascular leakage and that the observed increase in total protein concentrations in BAL fluid in the present study is induced by another mechanism. One possibility is that it is directly mediated by histamine, which is a well-known inducer of vascular leakage via $\mathrm{H}_{1}$ receptor mechanisms [35]. Evidence for a role of histamine in the vascular leakage is also indicated by the present study, as the levels of histamine in BAL fluid were markedly elevated together with BAL fluid protein in the L-NA-treated group compared to controls. Moreover, a positive correlation was found between histamine and total protein levels in BAL fluid, which further strengthens the case for a direct role of histamine in the increased vascular leakage.

BAL fluid histamine levels, $45 \mathrm{~min}$ after start of challenge, were significantly increased during the acute allergic reaction after L-NA pretreatment compared to the controls. BAL was performed after the peaks of histamine release occurred in urine, which would indicate that $45 \mathrm{~min}$ after challenge most of the histamine had been released and could be detected in the BAL fluid. The increased levels of histamine in the BAL fluid indicate that the mast cells were activated more strongly to release histamine when NO production was inhibited. This finding suggests that NO has a downregulating effect on histamine release from mast cells, which is also supported by other studies. For example, it was found that sodium nitroprusside, an NOgenerating drug, dose-dependently decreased histamine release from human skin [13] and bovine lung mast cells [36]. Moreover, L-NAME has been shown to enhance degranulation of rat [37] and guinea-pig mast cells [14]. NO seems to act as an intermediate in the regulation of mast cell function. Recently, it was shown that the suppressing effect of interferon- $\gamma$ and the stimulating effect of interleukin-gamma on mast cell responses are mediated via NO [38].

In addition to the increased histamine concentrations in the BAL fluid, a peak in histamine secretion in the urine was also found after allergen challenge. Although there wa.s no significant difference between the areas under the curves of urinary histamine levels in pigs pretreated with LNA and nontreated controls, and thus no differences in the total amount of histamine secreted via this pathway between the two groups, the peak was delayed in the L-NA group. This might be a result of the reduced BBF and, thus, a delayed clearance of the histamine that is released in the lungs during the acute allergic reaction. Delayed clearance probably also means that a larger proportion of the released histamine is metabolized before it ends up in the urine. This could explain why increased histamine levels were not detected in the urine of L-NA-treated animals. Impaired clearance of mediators due to vasoconstriction of the bronchial circulation might be yet another explanation for the increased reactions to antigen in the absence of NO. If the bronchoconstrictive mediators were retained in the lung longer, this might be expected to result in stronger and longer-lasting effects. This thought is in agreement with a study on dogs, which showed that the recovery time after i.v. infusion of histamine increases when the bronchial circulation is interrupted [39]. In this dog study, it was pointed out that the importance of the bronchial circulation in recovery after release of mediators in the lung is comparable to that of the pulmonary circulation, even though the bronchial circulation is only in the order of $1 \%$ of the pulmonary circulation [39]. This means that the bronchial circulation is an important factor to take into account when studying acute allergic reactions.

In conclusion, the present study showed that $N^{\mathrm{G}}$-nitro-Larginine enhanced the reactions that occur during the acute allergic reaction in the pig, which indicates a protective role of nitric oxide. The suggestion that nitric oxide's protective role is mainly mediated through its direct bronchodilating effect seems less likely, since in this study, only antigen-induced reactions were significantly affected by nitric oxide synthase inhibition and not histamineinduced reactions. Other explanations for the increased reactions to antigen in the absence of nitric oxide formation could be impaired clearance of bronchoconstrictive mediators due to vasoconstriction of the bronchial circulation and increased vascular leakage from the bronchial 
circulation. Clear signs of both bronchial vasoconstriction and increased vascular leakage were seen after $N^{\mathrm{G}}$-nitro-Larginine treatment. However, conflicting results have been reported with regard to the increased plasma leakage after nitric oxide synthase inhibition, and, were vasoconstriction alone responsible for increased airway reactions, the responses to histamine challenge after $N^{\mathrm{G}}$-nitro-L-arginine administration should also have been more pronounced. Thus, based on our results, we propose that one of the mechanisms through which nitric oxide could exert its protective effect is downregulation of histamine release from mast cells. This is supported by the marked increase in bronchoalveolar lavage fluid histamine levels following allergen sensitization in $N^{\mathrm{G}}$-nitro-L-arginine-treated pigs.

\section{References}

1. Gaston B, Drazen JM, Loscalzo J, Stamler JS. The biology of nitrogen oxides in the airways. Am J Respir Cril Care Med 1994; 149: 538-551.

2. Bernareggi M, Mitchell JA, Barnes PJ, Belvisi MG. Dual action of nitric oxide on airway plasma leakage. $A m \mathrm{~J}$ Respir Crit Care Med 1997; 155: 869-874.

3. Barnes PJ, Liew FY. Nitric oxide and asthmatic inflammation. Immunol Today 1995; 16: 128-130.

4. Alving K, Fornhem C, Weitzberg E, Lundberg JM. Nitric oxide mediates cigarette smokeinduced vasodilatory response in the lung. Acta Physiol Scand 1992; 146: 407-408.

5. Mehta S, Lilly CM, Rollenhagen JE, Haley KJ, Asano K, Drazon JM. Acute and chronic effects of allergic airway inflammation on pulmonary nitric oxide production. $\mathrm{Am} \mathrm{J}$ Physiol 1997; 272: L124-L131.

6. Guo FH, De Raeve HR, Rice TW, Stuchr DJ, Thunnisson FBJM, Erzyrum SC. Continuous nitric oxide synthesis by inducible nitric oxide synthase in normal human airway epithelium in vivo. Proc Natl Acad Sci USA 1995; 92: 7809-7813.

7. Ferreira HHA, Bevilacqua E, Gagioti SM, et al. Nitric oxide modulates eosinophil infiltration in antigen-induced airway inflammation in rats. Eur J Pharmacol 1998; 358 : 253-259.

8. Iijima H, Uchida Y, Endo T, et al. Role of endogenous nitric oxide in allergen-induced airway responses in guinea-pigs. Br J Pharmacol 1998; 124: 1019-1028.

9. Persson MG, Friberg SG, Gustafsson LE, Hadqvist P. The promotion of patent airways and inhibition of antigeninduced bronchial obstruction by endogenous nitric oxide. Br J Pharmacol 1995; 116: 2957-2962.

10. Nijkamp FP, Van der Linde HJ, Folkerts G. Nitric oxide synthesis inhibitors induce airway hyperresponsiveness in the guinea pig in vivo and in vitro - role of epithelium. Am Rev Respir Dis 1993; 148: 727-734.

11. Dupuy PM, Shore SA, Drazen JM, Frostell C, Hill WA, Zapol WM. Bronchodilator action of inhaled nitric oxide in guinea pigs. $J$ Clin Invest 1992; 90: 421-428.

12. Raud J, Dahlén S-E, Sydbom A, Lindbom L, Hedquist P. Enhancement of acute allergic inflammation by indomethacin is reversed by prostaglandin E2: apparent correlation with in vivo modulation of mediator release. Proc Natl Acad Sci USA 1988; 85: 2315-2319.

13. Van Overveld FJ, Bult H, Vermeire PA, Herman AG. Nitroprusside, a nitrogen generating drug, inhibits release of histamine and tryptase from human skin mast cells. Agents Actions 1993; 38: C237-C238.
14. Masini E, Gambassi F, Di Bello MG, Mugnai L, Raspanti $\mathrm{S}$, Mannaioni PF. Nitric oxide modulates cardiac and mast cell anaphylaxis. AgentsActions 1994; 41: C89-C90.

15. Fornhem C, Dahlbäck M, Kumlin M, Lundberg JM, Alving K. Effects of local and systemic budesonide on allergen-induced airway reactions in the pig. $\mathrm{Br} J$ Pharmacol 1996; 118: 989-997.

16. Alving K, Matran R, Fornhem C, Lundberg JM. Late phase bronchial and vascular responses to allergen in actively-sensitized pigs. Acta Physiol Scand1991; 143: 137-138.

17. Fornhem C, Lundberg JM, Alving K. Allergen-induced late-phase airways obstruction in the pig: the role of endogenous cortisol. Eur Respir J 1995; 8: 928-937.

18. Gade J, Norgaard MA, Andersen CB, Petterson G, Svendsen UG, Olsen PS. The porcine bronchial artery: surgical and angiographic anatomy. J Anat 1999; 194: 241-247.

19. Sartori C, Lepori M, Busch T, et al. Exhaled nitric oxide does not provide a marker of vascular endothelial function in healthy humans. Am J Respir Crit Care Med l 999; 160: 879-882.

20. Alving K, Weitzberg E, Lundberg JM. Increased amount of nitric oxide in exhaled air of asthmatics. Eur Respir $J$ 1993; 6: 1368-1370.

21. Kharitonov SA, Yates D, Robbins RA, Logan-SInclair R, Shinebourne E, Barnes PJ. Increased nitric oxide in exhaled air of asthmatic patients. Lancet 1994; 343: 133135.

22. Kharitonov SA, O'Connor BJ, Evans DJ, Barnes PJ. Allergen-induced late asthmatic reactions are associated with elevation of exhaled nitric oxide. Am J Respir Crit Care Med 1995; 151: 1894-1899.

23. Taylor DA, McGrath JL, O'Connor BJ, Barnes PJ. Allergen-induced early and late asthmatic responses are not affected by inhibition of endogenous nitric oxide. $\mathrm{Am}$ J Respir Crit Care Med 1998; 158: 99-106.

24. Alving K, Fornhem C, Lundberg JM. Pulmonary effects of endogenous and exogenous nitric oxide in the pig: relation to cigarette smoke inhalation. Br J Phamacol 1993; 110: 739-746.

25. Kannan MS, Johnson DE. Nitric oxide mediates the neural nonadrenergic, noncholinergic relaxation of pig tracheal smooth muscle. Am J Physiol 1992; 262: L511L514.

26. Belvisi MG, Stretton CD, Yacoub M, Barnes PJ. Nitric oxide is the endogenous neurotransmitter of bronchodilator nerves in humans. Eur J Pharmacol 1992; 210: 221-222.

27. Ellis JL, Conanan N. 1-citrulline reverses the inhibition of nonadrenergic, noncholinergic relaxations produced by nitric oxide synthase inhibitors in guinea pig trachea and human bronchus. J Pharmacol Exp Ther 1994; 269: 1073-1078.

28. Alving K, Matran R, Lacroix JS, Lundberg JM. Capsaicin and histamine antagonist-sensitive mechanisms in the immediate allergic reaction of pig airways. Acta Physiol Scand 1990; 138: 49-60.

29. Alving K. Airways vasodilatation in the immediate allergic reaction. Acta Physiol Scand 1991; 141: 1-64.

30. Persson MG, Gustafsson LE. Allergen-induced airway obstruction in guinea-pigs is associated with changes in nitric oxide levels in exhaled air. Acta Physiol Scand 1993; 149: 461-466.

31. Högman M, Frostell CG, Hedenström H, Hedenstierna G. Inhalation of nitric oxide moderates adult human 
bronchial tone. Am Rev Respir Dis 1993; 148: $1474-$ 1478.

32. McDonald DM. Endothelial gaps and permeability of venules in rat tracheas exposed to inflammatory stimuli. Am J Physiol 1994; 266: L61-L83.

33. Mehta S, Boudreau J, Lilly CM, Drazen JM. Endogenous pulmonary nitric oxide in the regulation of airway microvascular leak. Am J Physiol 1998; 275: L961-L968.

34. Erjefält JS, Erjefält I, Sundler F, Persson GGA. Mucosal nitric oxide may tonically suppress airways plasma exudation. Am J Respir Crit Care Med 1994; 150: 227-232.

35. Majno G, Shea SM, Leventhal M. Endothelial contraction induced by histamine-type mediators. J Cell Biol 1969; 42: 647-672.

36. Valentovic MA, Ball JG, Morcnas M, Szarek JL, Gruetter
CA. Influence of nitrovasodilators on bovine pulmonary histamine release. Pulm Pharmacol 1992; 5: 97-102.

37. Northover AM, Northover BJ. Inhibition of NO-synthase and degranulation of rat omental mast cells in vitro. Mediators Inflamm 1996; 5: 257-261.

38. Deschoolmeester ML, Eastmond NC, Dearman RJ, Kimber I, Basketter DA, Coleman JW. Reciprocal effects of interleukin-4 and interferon-g on immunoglobulin E-mediated mast cell degranulation: a role for nitric oxide but not peroxynitrite or cyclic guanosine monophosphate. Immunology 1999; 96: 138-144.

39. Kelly L, Kolbe J, Mitzner W, Spannhake EW, Bromberger-Barnea B, Mankes H. Bronchial blood flow affects recovery from constriction in dog lung periphery. J Appl Physiol 1986; 60: 1954-1959. 